\title{
Drought characteristics of Henan province in 1961-2013 based on Standardized Precipitation Evapotranspiration Index
}

\author{
SHI Benlin ${ }^{1}$, 'ZHU Xinyu ${ }^{1}$, HU Yunchuan², YANG Yanyan ${ }^{1}$ \\ 1. College of Environment and Planning, Shangqiu Normal University, Shangqiu 476000, Henan, China; \\ 2. College of Life Sciences, Shangqiu Normal University, Shangqiu 476000, Henan, China
}

\begin{abstract}
Drought is one of the most complex natural hazards affecting agriculture, water resources, natural ecosystems, and society. The negative societal consequences of drought include severe economic losses, famine, epidemics, and land degradation. However, few studies have analyzed the complexity of drought characteristics, both at multiple time scales and with variations in evapotranspiration. In this study, drought occurrences were quantified using a new drought index, the Standardized Precipitation Evapotranspiration Index (SPEI), based on observed data of monthly mean temperature and precipitation from 1961 to 2013 in Henan province, central China. Based on the SPEI values of each weather station in the study, the frequency and severity of meteorological droughts were computed, and the monthly, seasonal, and annual drought frequency and intensity over a 53-year period were analyzed. The spatial and temporal evolution, intensity, and the primary causes of drought occurrence in Henan were revealed. The results showed that the SPEI values effectively reflected the spatial and temporal pattern of drought occurrence. As the time scale decreased, the amplitude of the SPEI increased and droughts became more frequent. Since 1961, drought has occurred at the annual, seasonal, and monthly scales, and the occurrence of drought has increased. However, regional distribution has been uneven. The highest drought frequency, $35 \%$, was observed in the Zhoukou region, while the lowest value, $\sim 26 \%$, was measured in central and western Henan. The most severe droughts occurred in the spring and summer, followed by autumn. Annually, wide-ranging droughts occurred in 1966-1968, 1998-2000, and 2011-2013. The drought intensity showed higher values in north and west Henan, and lower values in its east and south. The maximum drought intensity value was recorded in Anyang, and the minimum occurred in Zhumadian, at $22.18 \%$ and $16.60 \%$, respectively. The factors with the greatest influence on drought occurrence are increasing temperatures, the Eurasian atmospheric circulation patterns, and the El Niño effect.
\end{abstract}

Keywords: Henan province; Standardized Precipitation Evapotranspiration Index; drought intensity; meteorological drought; climate change

Received: 2016-03-10 Accepted: 2016-05-21

Foundation: National Natural Science Foundation of China, No.41140019; No.41501263; The Key Program of Higher Education of Henan Province of China, No.15A180054

Author: Shi Benlin (1967-), Professor, specialized in regional ecological environment and agricultural ecology.

E-mail: shibenlin@163.com

*Corresponding author: Zhu Xinyu, PhD, E-mail: zhuxinyu@iga.ac.cn 


\section{Introduction}

As one of the most frequent and most complicated natural disasters, drought exerts relatively widespread effects on human society that usually last for several months or even a few years, causing huge economic loss, reduction in food yield, starvation and land degradation (Piao et al., 2010; Lobell et al., 2012; 2014; Asseng et al., 2015). As a country in the monsoon region of East Asia, China is climatically vulnerable to frequent meteorological disasters because of its geographical conditions and complex climatic changes (Jung et al., 2010). With the increasingly apparent climatic warming and drying, the occurrence of natural disasters increases considerably. It was noted in the 4th and 5th IPCC reports that the global surface temperature increased by 0.56 to $0.92^{\circ} \mathrm{C}$ during the past century and that climatic warming will enhance the frequency and intensity of the occurrence of extreme meteorological disasters, thus exerting extremely widespread effects on agricultural eco-systems (IPCC, 2007; IPCC, 2013). Therefore, quantitative studies on the characteristics of temporal and spatial drought changes and the mechanisms of their formation are of great importance for the scientific management of agricultural eco-systems and for early warning of meteorological disasters.

In recent years, many scholars proposed a variety of drought indices for quantitative studies on drought occurrence and for monitoring trends of drought change (Yuan et al., 2004; Wu et al., 2015; Karabulut, 2015). Currently, the PDSI (Palmer Drought Severity Index) and the SPI (Standardized Precipitation Index) cannot comprehensively reflect the joint effects of temperature and precipitation on drought occurrence under the global circumstances of climatic changes (Palmer, 1965; McKee et al., 1993; Dai, 2011). Therefore, on the basis of the SPI, the SPEI (Standardized Precipitation Evapotranspiration Index) was proposed and became the most useful tool for monitoring the effects of drought occurrence processes and rising temperatures on drought (Vicente-Serrano et al., 2010a; 2010b). In recent years, this index was gradually accepted and applied by Chinese scholars. Xiong et al. (2013) investigated the characteristics of drought changes in China's southwestern areas from 1961 to 2012 through adopting SPEI, and their results showed that drought has increased dramatically since 2000 in those areas. Using SPEI, Zhou et al. (2014) and Su et al. (2012) investigated the characteristics of drought occurrence in Shaanxi province and the relationship between low-frequency drought occurrence in Beijing and climatic indices. Li et al. (2010) adopted SPEI to investigate drought tendency in China from the late 1950s to 2009. These research results are in relative accordance with the historical records. As for the mechanisms for drought occurrence, investigations were mainly concentrated with the effects of land-air interactions on drought formation. However, changes in ocean temperature and the effects of large-scale annual climatic factors and climate warming on drought formation have become recognized as important factors (Mishra et al., 2010; Dai, 2011).

As a province located on the middle and lower reaches of the Yellow River, a middle-latitude zone in China, Henan province represents an area of transition between the subtropical zone and the warm temperate zone. Henan is characterized by extremely unevenly distributed precipitation and regular high temperatures, which usually generate frequent occurrences of meteorological disasters; drought is one of the most frequent natural 
disasters, with long duration and maximum area (Zhang et al., 2013). In recent years, increasing temperature and decreasing precipitation have aggravated the deterioration of the water resource environment of Henan. Additionally, since the 1970s the frequent seasonal channel cutoff of the Yellow River has brought about huge damage to the residents along the banks, leading to great loss in agricultural production and ecological environments. Therefore, the future trend and conditions of disaster development and the sustainable availability of water resources are of wide concern (Xu et al., 2014). Henan has become a main part of the Central Plains Economic Zone since its approval, and a typical agricultural area in the Huang-Huai-Hai Plain. Thanks to its unique geographical position, Henan has also become an important base for agricultural and sideline products, and for food production in China. Drought disasters exert relatively huge effects on agricultural development in Henan province. In recent years, studies on drought mainly focused on large-scale regional ranges and short time spans. Differences in views existed about the periodic occurrences of drought, their changing trend and causes and the effects of large-scale climatic factors on climatic components such as temperature and precipitation (Li et al., 2012). The comprehensive effects of drought indices were insufficiently researched in the main areas of agricultural crop production, and because of inadequate knowledge it is hard to comprehensively grasp the rules and mechanisms for the temporal and spatial changes in drought.

Because of the above-mentioned factors, we analyzed the frequency and intensity of drought occurrence in Henan province during the past 53 years and studied the characteristics of the temporal and spatial changes at various time scales on the basis of meteorological data consisting of daily temperatures and precipitation recorded from 1961 to 2013, and through the use of the drought index SPEI. The causes for drought in Henan were discussed to provide necessary support for policies concerning drought prevention and alleviation and to offer references for the evaluation, monitoring and forecast of drought situations in the future.

\section{Study area}

Henan province is located in the middle and lower reaches of the Yellow River in the central-east China, with a boundary ranging between $110^{\circ} 21^{\prime}-116^{\circ} 39^{\prime} \mathrm{E}$ and $31^{\circ} 23^{\prime}-36^{\circ} 22^{\prime} \mathrm{N}$ (Figure 1). As a province located in the warm temperate and subtropical zone, Henan is characterized by a humid and semi-humid monsoon climate featuring a cold winter with little rain and snow, a dry spring with frequent wind and blowing sand, a hot summer with abundant rains and a clear autumn with sufficient daily sunlight. The actual daily sunlight in the whole province ranges from 2000 to 2600 hours, average annual temperature ranges from $12^{\circ} \mathrm{C}$ to $16^{\circ} \mathrm{C}$ with the extreme maximum and minimum temperatures reaching $44.2^{\circ} \mathrm{C}$ and $21.7^{\circ} \mathrm{C}$, respectively. The frost-free period ranges from 180 to 240 days, and annual precipitation ranges from 500 to $900 \mathrm{~mm}$, which decreases gradually from southeast to northwest. Affected by the monsoon, precipitations are unevenly distributed in Henan, and 50\% of annual precipitation is concentrated in summer with frequent occurrences of heavy rains (Zhang et al., 2013). Four water systems, including the Yellow River, the Huaihe River, the Haihe River and the Yangtze River, flow across Henan (Fan et al., 2014). 


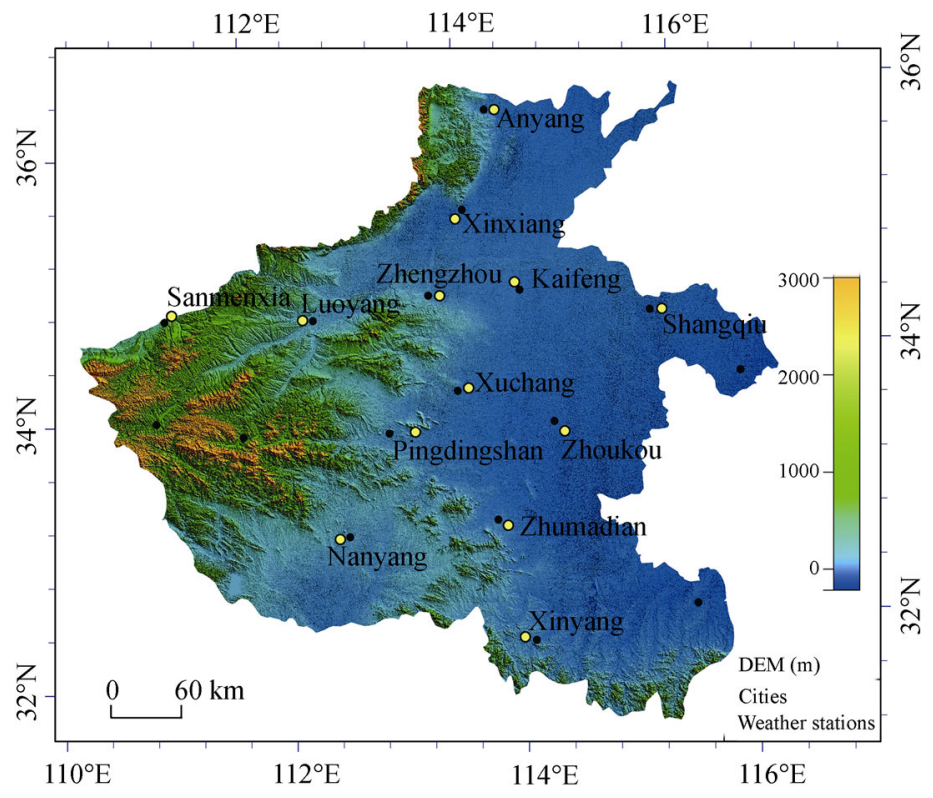

Figure 1 Distribution of meteorological stations in Henan province

\section{Material and methods}

\subsection{Data collection}

The county-level and above-county-level observatory stations were selected, and monthly data of precipitation and average temperature recorded through on-the-spot surveys from 1961 to 2013 and collected from 21 ground observatory stations were analyzed. Because the time period for the inaccuracies and shortages in surveys conducted by three stations exceeded 360 days, data from 53-year on-the-spot surveys collected from another 18 stations with better data quality were investigated (Figure 1). Among these stations, 6, 3, 3, 3 and 3 are in the north, east, west, south, and middle of Henan province, respectively. The even distribution of these stations shows a relatively good regional representation. The above-mentioned data were provided by the Henan Provincial Meteorological Bureau and the Shangqiu Municipal Meteorological Bureau. We studied monthly, quarterly and yearly time scales in this research. Spring was designated as the period from March to May, summer from June to August, autumn from September to November and winter from December to February of the next year.

\subsection{Methods}

(1) Standardized Precipitation Evapotranspiration Index (SPEI)

SPEI can be calculated as follows (Li et al., 2012):

First, potential evapotranspiration (PET) is calculated according to Thornthwaite's method:

$$
\operatorname{PET}_{i}=16.0 \times\left(\frac{10 T_{i}}{H}\right)^{A}
$$


where $A$ represents a constant, $H$ refers to annual heat index and $T_{i}$ represents 30 day average temperature. Constants $A$ and $H$ are calculated as follows:

$$
\begin{gathered}
A=6.75 \times 10^{-7} H^{3}-7.71 \times 10^{-5} H^{2}+1.792 \times 10^{-2} H+0.49 \\
H_{i}=\left(\frac{T_{i}}{5}\right)^{1.514} \\
H=\sum_{i=1}^{12} H_{i}=\sum_{i=1}^{12}\left(\frac{T_{i}}{5}\right)^{1.514}
\end{gathered}
$$

Second, the differences between annual monthly precipitation and evapotranspiration are calculated as:

$$
D_{i}=P_{i}-P E T_{i}
$$

where $D_{i}$ represents the difference between precipitation and evapotranspiration, $P_{i}$ and $P E T_{i}$ refer to monthly precipitation and evapotranspiration, respectively.

Third, $D_{i}$ data were sequentially normalized. $D_{i}$ is fitted using a log-logistic probability distribution $F(x)$, and SPEI values corresponding to each $D_{i}$ value were calculated according to formulas (7) and (8). If the cumulative probability $P \leqslant 0.5$, these values can be calculated as follows:

$$
\begin{gathered}
w=\sqrt{-2 \ln (P)} \\
\mathrm{SPEI}=w-\frac{c_{0}+c_{1} w+c_{2} w^{2}}{1+d_{1} w+d_{2} w^{2}+d_{3} w^{3}}
\end{gathered}
$$

where $d_{1}=1.432788, d_{2}=0.189269, d_{3}=0.001308, c_{0}=2.515517, c_{1}=0.802853$, and $c_{2}=$ 0.010328 .

If $P>0.5, P$ value can be represented by $1-P$ :

$$
\mathrm{SPEI}=-\left(w-\frac{c_{0}+c_{1} w+c_{2} w^{2}}{1+d_{1} w+d_{2} w^{2}+d_{3} w^{3}}\right)
$$

SPEI has characteristics of being calculated over particular time scales. The month-scale SPEI can relatively clearly reflect the delicate changes in drought processes, whereas the 3-month-scale SPEI can mirror the conditions of seasonal drought (Li et al., 2012). The average annual SPEI (month-scale) values of 18 meteorological stations can be adopted to represent month-scale SPEI values for Henan. Meteorologically, January, April, July and October are designated as representative months for winter, spring, summer and autumn, respectively. Therefore, the average SPEI values of these 4 months obtained from 18 stations were applied as season-scale SPEI values for Henan province. Altogether, the 12 monthly scales constitute an annual scale. The average SPEI value of these 18 meteorological stations was adopted as the average annual scale for SPEI values in this province.

(2) Probability of drought occurrence

The probability of drought occurrence $p$ can be calculated by the following:

$$
p=n / N \times 100 \%
$$

where $n$ refers to the frequency of drought occurrence in a data sequence, and $N$ represents the number of data points in the sequence. 
(3) Intensity of drought occurrence

In this research, a continuous 3-month occurrence of slight-level drought and above-slight-level drought (represented by the month-scale value of SPEI) was called a continuous drought process. According to the definition of a continuous drought process, month-scale values of SPEI in a continuous 3-month occurrence of slight-level drought and above-slight- level drought were selected, and month-scale values of SPEI were designated according to drought levels and probabilities described in the reference (Zhou et al., 2014) (Table 1), and the intensity of drought occurrence in the research area was calculated as the average value of the above-mentioned SPEI values.

Table 1 SPEI drought gradation hierarchies and corresponding cumulative probability

\begin{tabular}{lccccc}
\hline & $\begin{array}{c}\text { Extreme } \\
\text { drought }\end{array}$ & $\begin{array}{c}\text { Severe } \\
\text { drought }\end{array}$ & $\begin{array}{c}\text { Moderate } \\
\text { drought }\end{array}$ & $\begin{array}{c}\text { Slight } \\
\text { drought }\end{array}$ & $\begin{array}{c}\text { Normal } \\
\text { years }\end{array}$ \\
\hline SPEI value & $\leqslant-2.0$ & $\leqslant-1.5$ & $\leqslant-1.0$ & $\leqslant-0.5$ & -0.5 to 0.5 \\
Cumulative probability (\%) & 2.28 & 4.40 & 15.87 & 30.85 & 50.00 \\
\hline
\end{tabular}

\section{Results}

\subsection{Characteristics of various time scales of drought}

Rules for SPEI value fluctuation were significantly different for different time scales. With the expansion of time scales, such fluctuation gradually decreased, whereas the 3-monthscale fluctuation magnitude was relatively large from 1997 to 2002 (Figure 2). Month-scale SPEI values (SPEI-1) fluctuated within the maximum magnitude, 3-month-scale SPEI values (SPEI-3) had a slightly longer fluctuation period than that of SPEI-1, and 12-monthscale SPEI values (SPEI-12) remained relatively stable. Therefore, SPEI values under different time scales can reflect the changing conditions of drought and wetness in all parts of Henan. Affected by monthly temperature and changes in water conditions, SPEI-1 can reflect soil content more accurately and is applicable to the stipulation of drainage and irrigation periods for agricultural production. Affected by the effects of seasonal and annual precipitation and temperature, SPEI-3 and SPEI-12 can better mirror water contents within underground soil layers.

The changing trend of average SPEI values at different time scales from 1961 to 2013 was shown in Figure 3. It can be clearly seen that average annual SPEI-1 values fluctuated most smoothly, followed by average annual SPEI-3 values, and that average annual SPEI-12 values had maximum magnitude fluctuations. The SPEI-12-characterization of drought was in accordance with the historically recorded conditions in Henan. For example, the typical drought years in this province included 1966 (Severe Drought), 1978 (Moderate Drought), 1986 (Moderate Drought), 1997-1998 (Moderate-Slight Drought), 2000-2001 (Slight-Moderate Drought) and 2012-2013 (Moderate-Extreme Drought). Through the utilization of the Mann-Kendall mutation test (MK test), the average annual SPEI values in Henan recorded from 1961 to 2013 were analyzed, and the results are shown in Figure 4. It is obvious that most UF values were below 0, with a trend of decrease-increase-decrease and a general trend of slow decrease within fluctuations (Figure 4). In the 1980s, the UF value began to mutate and decrease; the concrete mutation point occurred in 1987. 
Within the range of the confidence test line, mutation points appeared in 1965, 1983 and 2008, respectively.

\subsection{Characteristics of the spatial distribution of drought}

At the seasonal scale, spring droughts mainly occurred in the east, south and north of Henan with relatively huge differences among different regions (Figure 5). The maximum frequency of spring drought, over $35 \%$, appeared in Zhoukou, followed by values in Pingdingshan and Zhumadian, reaching over 33\%; values in the middle and west of Henan province were the minimum, approximately $26 \%$. Summer droughts occurred more frequently than spring droughts, with slight differences among different regions. The low frequency of summer drought occurrence appeared in the west of Henan province, reaching approximately $30 \%$. The maximumfrequency of summer drought occurrence was in the south of Henan, approaching $40 \%$, and the frequency of summer drought occurrence in other parts of Henan ranged from $30 \%$ to $35 \%$. The frequency of autumn drought occurrence was over $35 \%$ throughout the province except for the southwest and Xinyang in the south of Henan
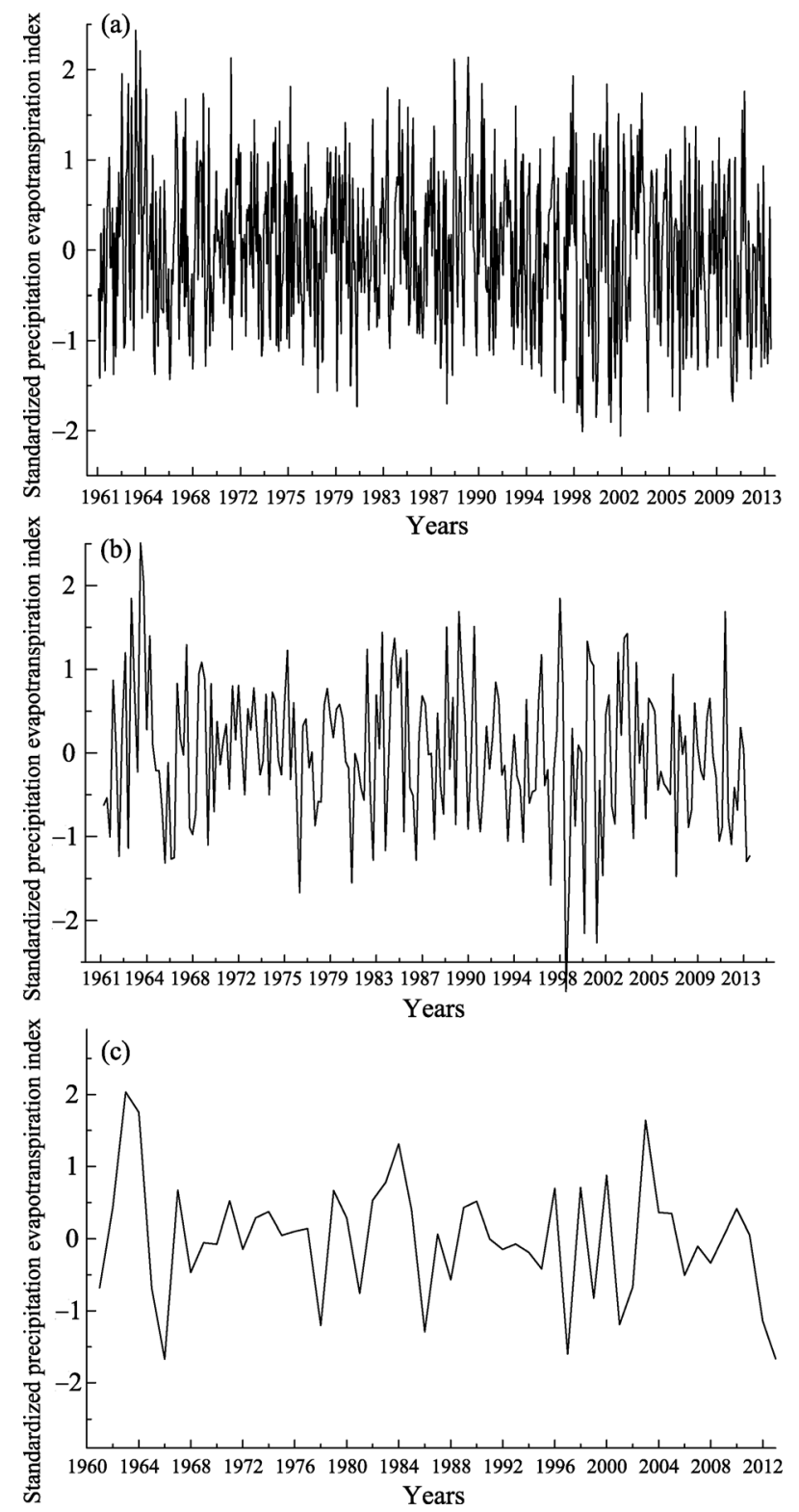

Figure 2 SPEI values at different time scales in Henan from 1961 to 2013

(Note: A, B, and C represent month-scale, season-scale, and year-scale SPEI values, respectively) province, where the frequency of autumn drought occurrence ranged from $26 \%$ to $28 \%$. Therefore, the frequency of autumn drought occurrence was generally lower than that of summer drought occurrence with relatively small regional differences. The frequency of winter drought occurrence was higher in the east than in the west, with relatively large differences. The frequency of winter drought occurrence was relatively higher in the north and east of Henan province, approximately $35 \%$ to $37 \%$, with values in the middle and southwest of Henan province ranging from $30 \%$ to $33 \%$ and relatively low values in the west of 


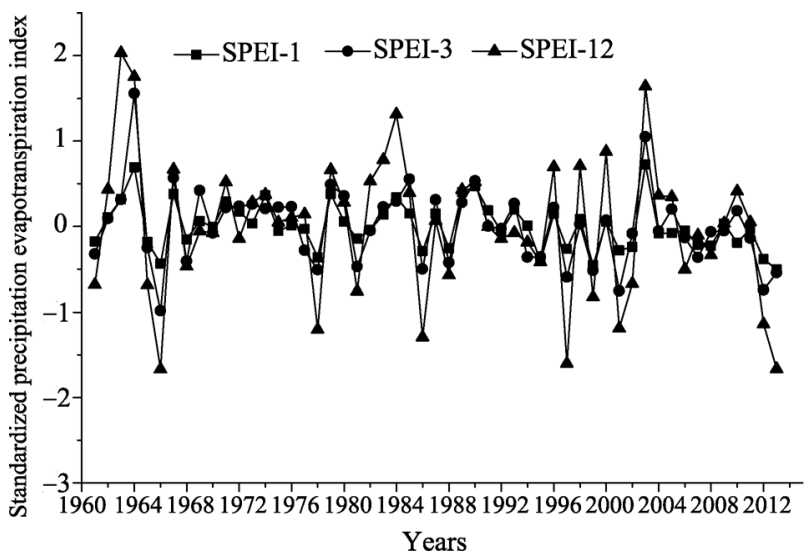

Figure 3 The annual SPEI values at different time scales in Henan from 1961 to 2013

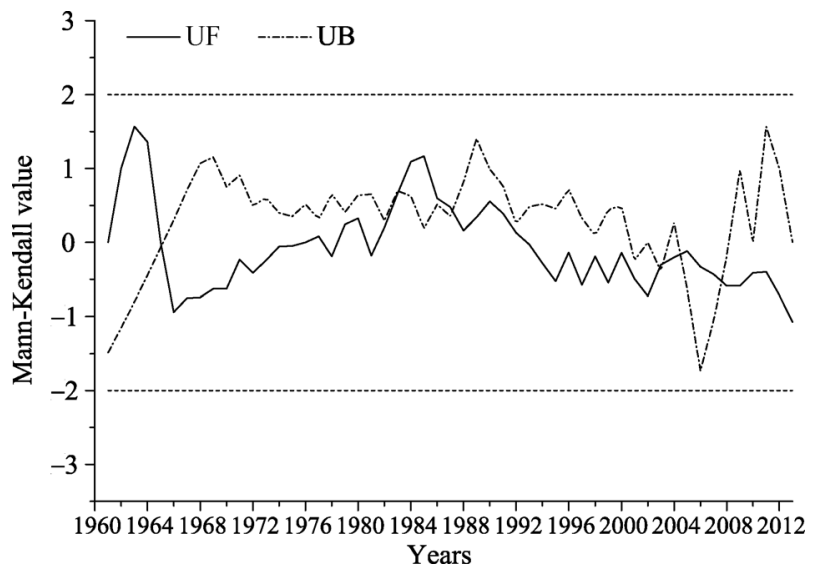

Figure 4 Mann-Kendall test for annual SPEI-12 series in Henan from 1961 to 2013

Henan province, especially in Sanmenxia where the frequency of winter drought occurrence was only $22.64 \%$.

At the monthly scale, the frequency of drought occurrence was generally high, all having values over $32 \%$. The maximum values were over $35 \%$ in the north and east of Henan, while they were relatively low in the west, southwest and south of Henan and were a minimum of approximately $32 \%$ in Xinxiang, Luoyang and Xinyang. Regional differences were relatively small at the monthly scale of drought occurrence frequency in Henan province.

At the annual scale, the frequency of drought occurrence was relatively high in the west, southwest and south of Henan province, all more than $35 \%$, and was relatively low in the north, middle and east of Henan province, especially in Zhengzhou where the minimum was approximately $24 \%$. Regional differences were relatively large at the annual scale of drought occurrence frequency and unevenly distributed in Henan province.

\subsection{Distribution of drought occurrence intensity}

\subsubsection{Occurrence of continuous drought}

Among the areas that had over 3 months of continuous drought occurrence, Zhengzhou was 

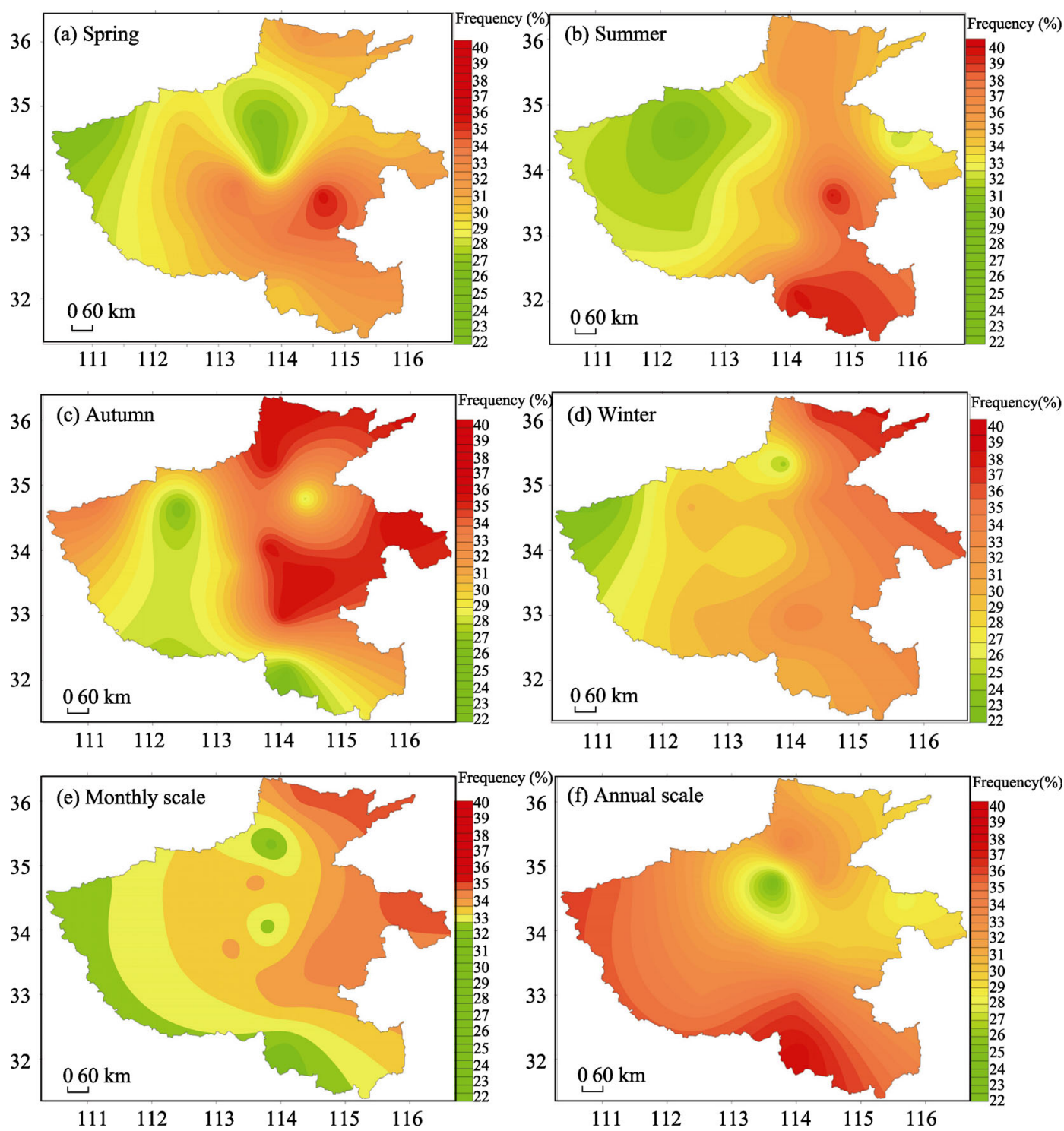

Figure 5 Drought frequency distribution at different scales in Henan

the one that had the most frequent occurrence, 23 over the past 53 years. Meanwhile, Xuchang, Luoyang and Sanmenxia had the least frequent droughts, 12-13. The longest drought duration appeared in Xihua County in the southwest of Zhoukou in 1986, lasting 8 months (within 1 drought). Frequency of over 5 months of continuous drought occurrence was 25, including 9 occurrences in the 1960s (in 1961, 1965, 1966 and 1968), 2 occurrences in the 1980s (concentrated in 1968), 7 occurrences in the 1990s (in 1992, 1997 and 1998-1999) and 7 occurrences from 2000 to 2013 (4 in 2013, 1 in 2001, 1 in 2008-2009 and 1 in 2011). Therefore, in the 1960s, 1990s and 2013, a large range of continuous drought occurred in Henan province, which was relatively in line with the actual conditions.

It is shown that the intensity of drought occurrence in Henan province was the minimum in the east and south, followed by the west and middle, and the value was the maximum in 
the north (Figure 6). Zhumadian in the south of the province had the weakest intensity of drought occurrence, $16.60 \%$, followed by values reaching $17.52 \%$ and $17.70 \%$ in Shangqiu and Xuchang, respectively, both lower than $20 \%$. Anyang in the north of Henan province had the strongest intensity of drought occurrence, $22.18 \%$, followed by values of $21.12 \%$ and $20.23 \%$ in Kaifeng in the east and Pingdingshan in the west, respectively.

4.3.2 Distribution of moderate and

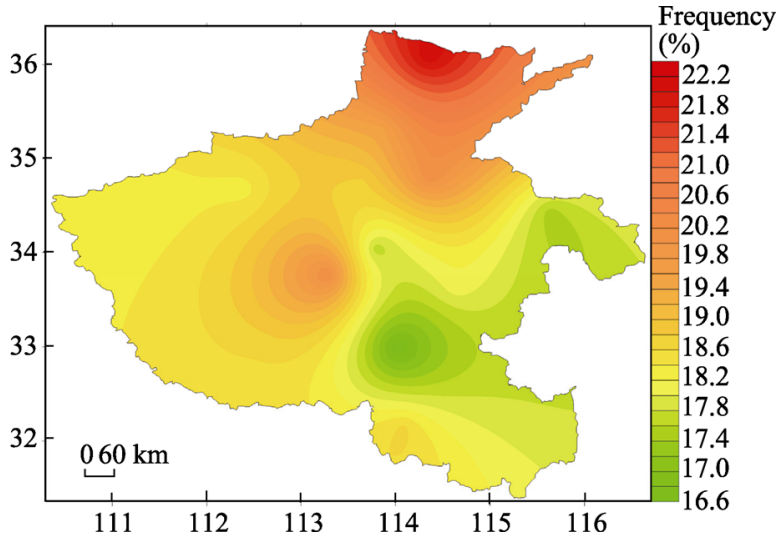

Figure 6 Spatial distribution characteristics of drought intensity in Henan above-moderate droughts

It is shown that in spring, moderate and above-moderate droughts mainly occurred in the east of eastern Henan province and the north of southern Henan, and relatively rarely occurred in the southwest of northern Henan and the south of southern Henan (Figure 7a). Shangqiu in the east of Henan and Zhumadian in the south of Henan had the maximum frequencies of drought occurrence, both amounting to more than $20 \%$. Xinyang in the south of Henan had the minimum frequency of drought occurrence, less than $10 \%$. Frequency of drought occurrence in other parts of Henan ranged from $11 \%$ to $18 \%$ with relatively large regional differences. In summer, moderate and above-moderate droughts mainly occurred in the middle of Henan (Figure $7 \mathrm{~b}$ ). Xuchang in the middle of Henan had the maximum frequency of drought occurrence, $22.64 \%$, whereas Xinyang in the same area had the minimum frequency of drought occurrence, $11.32 \%$. Meanwhile, frequencies of drought occurrence in other parts ranged from $15 \%$ to $18 \%$ with regional differences smaller than those in spring. In autumn, the frequency of moderate and above-moderate drought occurrence was generally low (Figure 7c). Kaifeng in the east of the province had the maximum frequency, $18.87 \%$, whereas Xuchang in the middle of the province had the minimum frequency, less than $10 \%$, and frequencies of drought occurrence in other parts ranged from $11 \%$ to $16 \%$ with slight regional differences. In winter, there were relatively large regional differences in the occurrence frequency of moderate and above-moderate droughts, with high frequencies in the east and low frequencies in the west (Figure 7d). Anyang in the north and Zhoukou in the middle of Henan province had the maximum frequencies of moderate and above-moderate drought occurrence, both $20.75 \%$, followed by Xinyang in the south, with $18.87 \%$. Sanmenxia in the west of Henan province had the lowest value, only $7.55 \%$, and values in other parts ranged from $11 \%$ to $15 \%$.

At the monthly scale, the frequency of drought occurrence was higher in the east and middle of Henan province and was lower in the north, south and west, with relatively small regional differences (Figure 7e). Shanqgiu in the east had the highest frequency of drought occurrence, $21.22 \%$, followed by Zhoukou in the east, with $19.81 \%$, whereas Xinxiang in the north and Kaifeng in the east had the highest frequencies of drought occurrence, both with $16.35 \%$; in other parts, the values ranged from $16 \%$ to $18 \%$. 

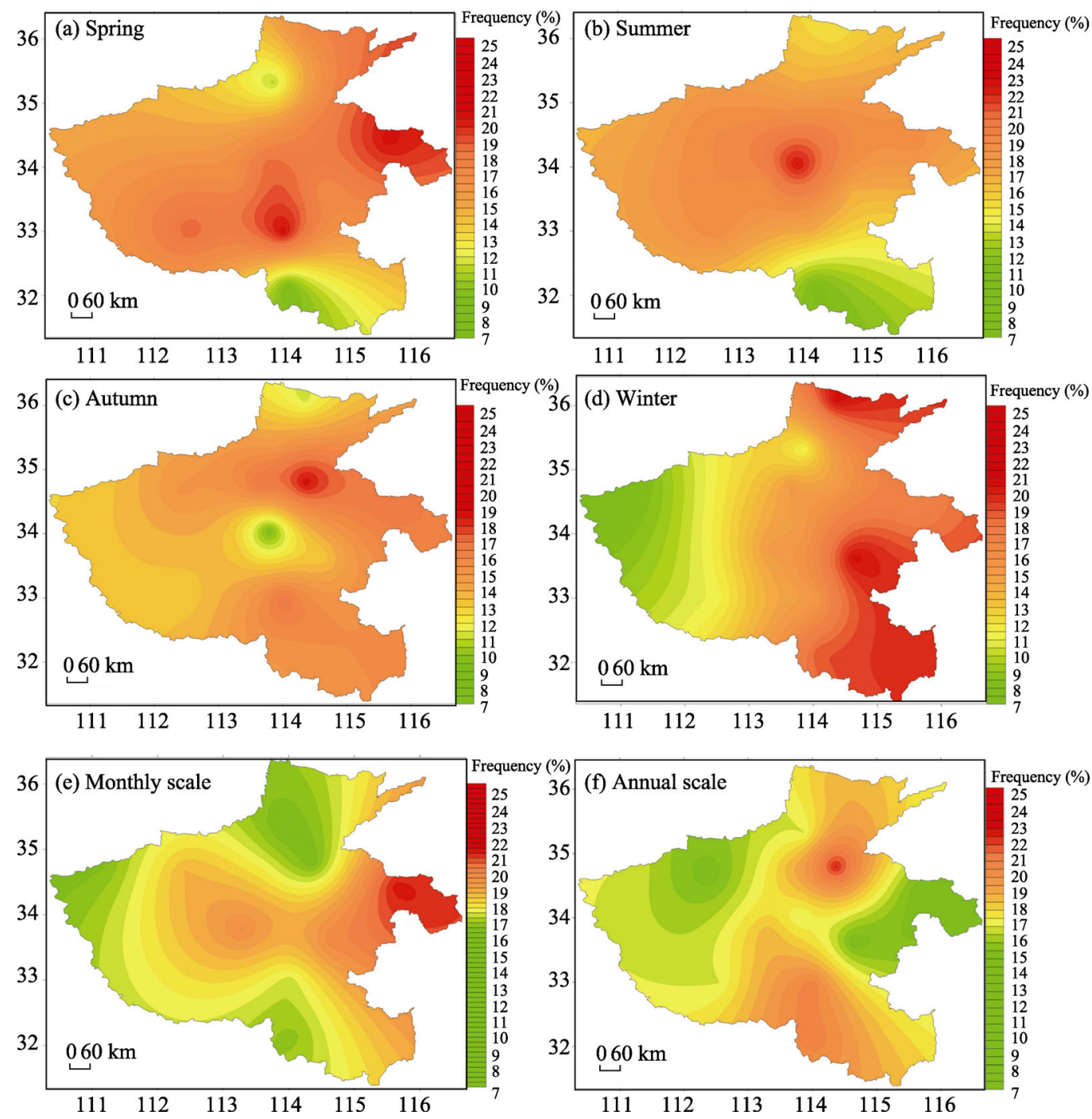

Figure 7 Moderate or above drought frequency distribution at different scales in Henan

At the annual scale, the frequency of drought occurrence was higher in the north and south of Henan province and was lower in the east and west with relatively small regional differences (Figure 7f). Kaifeng in the east had the highest frequency of drought occurrence, amounting to $22.64 \%$, followed by Zhumadian and Xinxiang in the south, both with $20.75 \%$, whereas Shangqiu and Zhoukou in the east and Luoyang in the west had the lowest frequency of drought occurrence, $15.09 \%$.

\section{Discussion}

(1) The SPEI values at different time scales recorded over the recent 53-year period shows that drought trends have increased significantly since the 1980 s. According to the MK mutation test and within confidence test lines, mutation points occurred in 1965, 1983 and 2008 , and the occurrences of drought at these points were in accordance with the actual 
conditions (EBMDC, 2005). When the annual scale SPEI value in the testing year gradually changed into a relatively low value, relatively severe drought would appear, which was mainly because different fluctuation amplitudes, periods and initial positions of SPEI values at different time scales may bring about severe droughts caused by the superposition of different time scales of droughts at particular time points. Meanwhile, at short time scales (3 months), SPEI values mainly exhibited seasonal scale changes, and when SPEI values at annual scales were relatively lower, such values would accumulate with those at short time scales, thus causing extreme droughts.

(2) Seasonal droughts in Henan province are relatively severe in spring and summer, moderate in autumn, and the weakest in winter. As a core pilot area for food production in the Central Plain Economic Zone, Henan province demands relatively large amounts of water. However, precipitation in Henan is unevenly distributed, mainly concentrates in July and August and is not very abundant. Additionally, relatively small amounts of rainfall in summer with relatively large annual changes, precipitation reduction and temperature increase over the recent 53-year period have resulted in relatively severe drought in spring and summer (Zhu et al., 2012; Shi et al., 2012; Xu et al., 2014). Moreover, drought represents a major relatively frequent meteorological disaster in Henan province. Since the founding of New China, severe spring droughts, summer droughts and continuous droughts have occurred in 1966-1968, 1998-2000 and 2011-2013 in Henan province (EBMDC, 2005). Since the beginning of the 21 st century, temperatures in a vast number of areas in China have been increasing and are higher than those at the same period of the non-drought years. Average monthly temperatures in drought areas of north China increased by $0.5-2^{\circ} \mathrm{C}$ compared with those in non-drought years. Increasing temperatures caused the acceleration of soil water evaporation, which further promotes the rapid development of drought conditions in combination with the occurrence of El Nino phenomena (Sutanto et al., 2015).

(3) Henan province, located in the middle and lower reaches of the Yellow River, namely the transition area of south and north climates and of the secondary and tertiary gradients from east to west, represents an important base for food production in the Central Plains Economic Zone. Frequent meteorological disasters (especially drought) occurring after the founding of New China greatly restrained food production and sustainable development in this zone (Zhu et al., 2012). In the most recent 50 years, the trend of climatic warming was relatively obvious in this zone with huge precipitation fluctuations and frequent drought disasters (Shi et al., 2012). Relevant research showed that the trend of climatic warming was obvious in Henan province over the past 50 years, with huge precipitation fluctuations and with temperature increase and precipitation reduction bringing about more frequent droughts (Shi et al., 2012; Zhang et al., 2013). The results of Xu et al. (2014) showed that in spring and summer in the Huang-Huai-Hai Plain, the increasing temperature led to an increasing tendency for drought occurrence. Additionally, evaporation in spring was far greater than precipitation. Since late October, 2008, no effective rainfall had appeared in Henan province within 100 days and precipitation from 2008 to 2009 was extremely small in Henan's historical record; meanwhile, extremely severe droughts afflicted $63.1 \%$ of the area of Henan province (2009-02-04). According to the characteristics of atmospheric circulation in typical drought-occurring years and due to the strong stability of atmospheric circulation in Eurasia, the seasonal changes in the intensity and location of western Pacific subtropical high pres- 
sure zones and Siberian high pressure zones could readily bring about droughts in the middle and lower reaches of the Yellow River (Xu et al., 2014). Abnormal atmospheric circulation led to relatively weak cold and hot air masses that could not converge at the basins of the Yellow River and Huaihe River, thus causing the occurrence of droughts in Henan province. In addition, the relatively weak warm and wet airflow over Henan also affected the occurrence of droughts. For example, from the end of 2008 to 2009, the prevailing northwest airflow over Henan was accompanied by dry and cold air and winds, whereas southwest warm and wet airflow, which can bring about effective precipitation, did not appear. Effective precipitation cannot come only from dry and cold air; therefore, drought can develop and be maintained (2009-02-04). ENSO (El Nino phenomenon) is the main embodiment of the interactions between sea and air, and exerts relatively large effects on drought disasters in Henan province. From the comparison analysis of ENSO events occurring in the past decades and drought conditions in the study area (Sutanto et al., 2015), our results clearly show that the occurrence of ENSO events was closely related to drought occurrence in Henan province, and the fact that drought occurred in the same year or in the year following ENSO occurrence became a general rule. For example, ENSO events that occurred from 1965 to 1966, from 1997 to 1998 and from 2009 to 2010 were closely related to the occurrences of large-range continuous drought from 1966 to 1968, from 1998 to 2000 and from 2011 to 2013, respectively, indicating that ENSO events increased the frequency of drought occurrence.

(4) In this paper, through the adoption of SPEI, the rules for the temporal and spatial changes of drought over the recent 53-year period in Henan province were analyzed at various time scales. SPEI integrated the roles of evapotranspiration in the formation of drought and, in the recognition of the characteristics of drought occurrence in Henan province over the past 53 years, better embodied the responses of drought to global warming since the 1980s. SPEI provides a necessary basis for the monitoring and early warning of drought occurrences in other regions. However, if SPEI is applied, the annual precipitation in the research area should also be considered. The results of Zhuang et al. (2013) showed that SPEI cannot better reflect the conditions of regional drought monitoring in areas where annual precipitation amounts to less than $200 \mathrm{~mm}$ because relatively small evapotranspiration and precipitation bring about limitations in analyses at small scales (such as 1-month, 3-month and 6-month scales). The annual precipitation in Henan province ranges from $500 \mathrm{~mm}$ to $900 \mathrm{~mm}$. Therefore, SPEI can better reflect the rules for the temporal and spatial changes of drought in the recent 53 years in Henan province. Additionally, given that the scale classifications of the SPEI drought indices were not constant values, the conditions of scale classifications in different regions were diverse, which led to ambivalences in evaluating the frequency and grade of drought occurrences. Therefore, research concerning this aspect should be strengthened in the future. In this paper, drought formation and its mechanisms of occurrence were discussed from such aspects as global climatic changes, atmospheric circulations, and ENSO phenomena. However, drought formation is related to a variety of factors, for example, water resource conditions, human activities, geomorphology, relative humidity and wind speed, which have relatively large effects on drought formation (Barnett et al., 2008; Xu et al., 2014). Therefore, issues concerning the mechanism of drought occurrence and the 
detailed causes of small-range disaster occurrence should be of urgently concern in the future.

\section{Conclusions}

(1) The rules for the fluctuation of SPEI values in Henan province in the past 53 years were different at different time scales, and SPEI values fluctuated with huge amplitudes at smaller time scales, demonstrating that such values can better reflect the temporal characteristics of drought changes and the conditions of dryness and wetness evolution in Henan province. It was shown in MK mutation tests that drought increased significantly in Henan province after 1987.

(2) Frequency of drought occurrence was higher at monthly scales than at annual scales, and drought was more severe in spring and summer, followed by drought in autumn. Drought occurrences were extremely unevenly distributed among different regions, the highest drought frequency, 35\%, was observed in Zhoukou, while the lowest value, 26\%, was measured in the middle and west of Henan province.

(3) With respect to the characteristics of the distribution of drought occurrence intensities, such intensities were higher in the north of Henan province and in the east of western Henan province, and lower in the east of Henan province and in the north of southern Henan province. The maximum drought intensity value was recorded in Anyang, and the minimum occurred in Zhumadian, at $22.18 \%$ and $16.60 \%$, respectively. In the inter-annual variations, from 1966 to 1968, from 1998 to 2000 and from 2011 to 2013, vast ranges of continuous droughts occurred in Henan province, and Anyang and Pingdingshan had the maximum intensities of drought occurrence.

\section{References}

Asseng S, Ewert F, Martre P et al., 2015. Rising temperatures reduce global wheat production. Nature Climate Change, 5(2): 143-147.

Barnett T P, Pierce D W, Hidalgo H G et al., 2008. Human-induced changes in the hydrology of the Western United States. Science, 319(5866): 1080-1083.

Dai A G, 2011. Drought under global warming: A review. Wiley Interdisciplinary Reviews. Climate Change, 2(1): $45-65$.

Editorial Board of Meteorological Disasters in China (EBMDC), 2005. The Meteorological Disasters in China $\cdot$ Henan Volume. Beijing: China Meteorological Press, 11-116. (in Chinese)

Fan Q D, Liang G F, Ma S X, 2014. Analysis on ecosystem service change based on land use in Henan province. Journal of Henan Agricultural University, 48(2): 224-228. (in Chinese)

IPCC, 2007. Climate Change 2007: The Physical Science Basis, Summary for Policy Makers. Paris: IPCC WGI Fourth Report, 195-199.

IPCC, 2013. Working Group I Contribution to the IPCC Fifth Assessment Report, Climate Change 2013: The Physical Science Basis: Summary for Policymakers. [2013-10-28]. http://www.climatechange2013.org/images/uploads/WGIAR5-SPM_Approved27Sep2013.pdf

Jung M, Reichstein M, Ciais P et al., 2010. Recent decline in the global land evapotranspiration trend due to limited moisture supply. Nature, 467(7318): 951-954.

Karabulut M. 2015. Drought analysis in Antakya-Kahramanmaraş Graben, Turkey. Journal of Arid Land, 7(6): 
741-754.

Li W G, Hou M T, Chen H L, 2012. Study on drought trend in south China based on standardized precipitation evapotranspiration index. Journal of Natural Disasters, 21(4): 84-90. (in Chinese)

Lobell D B, Roberts M J, Schlenker W S et al., 2014. Greater sensitivity to drought accompanies Maize yield increase in the U.S. Midwest. Science, 344(6183): 516-519.

Lobell D B, Sibley A, Ortiz-Monasterio J I, 2012. Extreme heat effects on wheat senescence in India. Nature Climate Change, 2(3): 186-189.

McKee T B, Doesken N J, Kleist J, 1993. The relationship of drought frequency and duration to time scales // Proceedings of the 8th Conference on Applied Climatology. Boston, MA: American Meteorological Society, 17(22): 179-183.

Mishra A K, Singh V P, 2010. A review of drought concepts. Journal of Hydrology, 391(1/2): 202-216.

Palmer W C, 1965. Meteorological Drought. Washington DC, USA: US Department of Commerce, Weather Bureau.

Piao S L, Ciais P, Huang Y et al., 2010. The impacts of climate change on water resources and agriculture in China. Nature, 467(2): 43-51.

Rare drought occurred in the history of China and nearly forty percent of winter wheat was afflicted. http://www.chinanews.com/gn/news/2009/02-04/1549588.shtml, 2009-02-04. (in Chinese)

Shi B L, Zhu X Y, Li H Z et al., 2012. Impacts of climate change on winter wheat yield in central plains of China: Case study of Shangqiu. Geographical Research, 31(1): 14-22. (in Chinese)

Su H X, Li G Q, 2012. Low-frequency drought variability based on SPEI in association with climate indices in Beijing. Acta Ecologica Sinica, 32(17): 5467-5475. (in Chinese)

Sutanto S J, Hoffmann G, Worden J et al., 2015. Atmospheric processes governing the changes in water isotopologues during ENSO events from model and satellite measurements. Journal of Geophysical Research Atmospheres, 120(13): 6712-6729.

Vicente-Serrano S M, Beguería S, López-Moreno J I, 2010a. A multiscalar drought index sensitive to global warming: the standardized precipitation evapotranspiration index. Journal of Climate, 23(7): 1696-1718.

Vicente-Serrano S M, Beguería S, López-Moreno J I et al., 2010b. A new global 0.5 gridded dataset (1901-2006) of a multiscalar drought index: Comparison with current drought index datasets based on the Palmer Drought Severity Index. Journal of Hydrometeorology, 11(4): 1033-1043.

Wu Y F, Bake B, Zhang J S et al., 2015. Spatio-temporal patterns of drought in North Xinjiang, China, 1961-2012 based on meteorological drought index. Journal of Arid Land, 7(4): 527-543.

Xiong G J, Zhang B K, Li C Y et al., 2013. Characteristics of drought variations in Southweat China in 1961-2012 based on SPEI. Advances in Climate Change Research, 9 (3): 192-198. (in Chinese)

$\mathrm{Xu} \mathrm{J}$ W, Ju H, Liu Q et al., 2014. Variation of drought and regional response to climate change in Huang-Huai-Hai Plain. Acta Ecologica Sinica, 34(2): 460-470. (in Chinese)

Yuan W P, Zhou G S, 2004. Theoretical study and research prospect on drought indices. Advances in Earth Science, 19(6): 982-991. (in Chinese)

Zhang J J, Guo Z F, Li Z G, 2013. Research on time and spatial characteristics of flood and drought disasters risk in Henan. Journal of Natural Resources, 28(6): 957-968. (in Chinese)

Zhou D, Zhang B, Ren P G et al., 2014. Analysis of drought characteristics of Shaanxi province in recent 50 years based on Standardized Precipitation Evapotranspiration Index. Journal of Natural Resources, 29(4): 677-688. (in Chinese)

Zhu X Y, Liu J, Shi B L et al., 2012. Variation of climate suitability of winter wheat in central plains under the condition of climate warming. Geographical Research, 31(8): 1479-1489. (in Chinese)

Zhuang S W, Zuo H C, Ren P C et al., 2013. Application of standardized precipitation evapotranspiration index in China. Climatic and Environmental Research, 18(5): 617-625. (in Chinese) 